Article

\title{
Bilobalide Suppresses Adipogenesis in 3T3-L1 Adipocytes via the AMPK Signaling Pathway
}

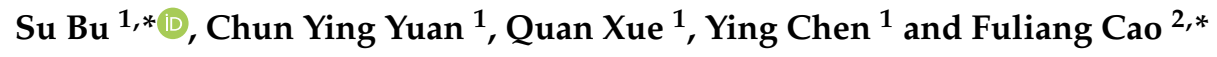 \\ 1 College of Biology and the Environment, Nanjing Forestry University, Nanjing 210037, China; \\ yuancy100294@outlook.com (C.Y.Y.); iyiudty@gmail.com (Q.X.); chynjfu@163.com (Y.C.) \\ 2 Co-innovation Center for Sustainable Forestry in Southern China, Nanjing Forestry University, \\ Nanjing 210037, China \\ * Correspondence: susanabu2014@163.com (S.B.); cao@njfu.edu.cn (F.C.)
}

Received: 5 August 2019; Accepted: 19 September 2019; Published: 27 September 2019

\begin{abstract}
Bilobalide, the only sesquiterpene compound from Ginkgo biloba leaf, exhibits various beneficial pharmaceutical activities, such as antioxidant, anti-inflammation, and protective effects for the central nervous system. Several bioactive components extracted from Ginkgo biloba extract reportedly have the potential to attenuate lipid metabolism. However, the effect of bilobalide on lipid metabolism remains unclear. In this study, we used 3T3-L1 cells as the cell model to investigate the effect of bilobalide on adipogenesis. The results showed that bilobalide inhibited 3T3-L1 preadipocyte differentiation and intracellular lipid accumulation. Quantitative real-time PCR and western blotting results indicated that several specific adipogenic transcription factors and a few important adipogenesis-related genes were significantly down regulated on both mRNA and protein levels in bilobalide treatment groups. By contrast, the expression of some lipolytic genes, such as adipose triglyceride lipase, hormone-sensitive lipase $(H S L)$, and carnitine palmitoyltransferase- $1 \alpha$, were all up-regulated by bilobalide treatment, and the phosphorylation of AMP-activated protein kinase (AMPK), acetyl-CoA carboxylase 1, and HSL were stimulated. Furthermore, bilobalide treatment partially restored AMPK activity following its blockade by compound C (dorsomorphin). These results suggested that bilobalide inhibited adipogenesis and promoted lipolysis in 3T3-L1 cells by activating the AMPK signaling pathway.
\end{abstract}

Keywords: bilobalide; 3T3-L1 cell; lipid metabolism; AMPK pathway

\section{Introduction}

Obesity is becoming a serious health problem in many countries and poses a major economic challenge worldwide. Obesity has transformed from a disease with high incidence in economically developed regions to a global chronic disease [1-4] that can lead to a number of serious complications, including type 2 diabetes (T2D), metabolic syndrome, some types of cancer, neurodegeneration, and cardiovascular diseases $[5,6]$. The proliferation of preadipocytes and lipid accumulation in adipocytes are the main causes of obesity [7].

Bioactive components from Ginkgo biloba have long been the focus of attention due to their high levels of pharmaceutical activities [8,9]. Bilobalide is a sesquiterpene compound (Figure 1) and the only one found in Ginkgo biloba [10]. Sesquiterpenes are one kind of important raw material used by the pharmaceutical industry and are ubiquitous in nature. Bilobalide is an intermediate metabolite of ginkgolides and is capable of inhibiting apoptosis, protecting injured cells, and protecting the brain from damage [11-14]. Ginkgolide A (GA) has been implicated in mitochondrial oxidative stress and inducing cellular lipoapoptosis [15], and also ginkgolide C reportedly exerts an inhibitory effect on lipid accumulation in liver hepatocellular carcinoma (HepG2) cells [16]. As the analogue of ginkgolides 
C and B, bilobalide might exhibit similar biological activity; therefore, in this study, we explored its effect on lipid metabolism.

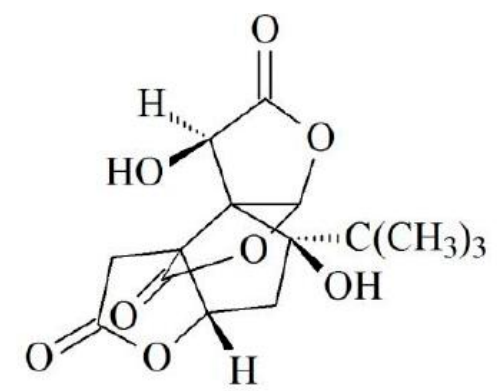

Figure 1. Chemical structure of Bilobalide.

Lipid storage in white adipose tissue (WAT) is controlled by the dynamic processes of lipogenesis and lipolysis, which involve many transcription factors, enzymes, and proteins. Among them, CCAAT enhancer binding protein alpha (C/EBP $\alpha$ ), sterol regulatory element binding protein 1c (SREBP-1c), and peroxide proliferative activation receptor gamma (PPAR $\gamma$ ) are key transcription factors responsible for end-phase differentiation and regulation of a large number of downstream genes involved in lipid metabolism [17,18]. AMP-activated protein kinase (AMPK) signaling is the key pathway of lipid metabolism. The $\beta$ oxidation of fatty acids, lipid hydrolysis of triglycerides, and lipid production by adipocytes are regulated by the AMPK pathway [19]. Activation of this pathway requires AMPK phosphorylation, resulting in inhibition of lipid synthesis and upregulation of lipid hydrolysis and $\beta$ oxidation of fatty acids [20]. Some proteins located downstream of the AMPK pathway, including acetyl coenzyme A carboxylase 1 (ACC1), sterol regulatory element binding protein 1c (SREBP-1c), glucose transporter 4 (GLUT-4), and carnitine palmitoyltransferase 1A (CPT1 $\alpha)$, are all highly involved in lipid metabolism. ACC1 is a key rate-limiting enzyme in the first stage of fatty acid synthesis and promotes the synthesis of long-chain fatty acids, as well as the synthesis of triglycerides and phospholipids [21]. SREBP-1c increases intracellular cholesterol concentrations by enhancing the expression of cholesterol-binding receptors on the cell membrane surface [20]. GLUT-4, mainly found in fat and muscle tissue, regulates the uptake of glucose from extracellular cells after insulin stimulation [22]. CPT1 $\alpha$ is located in the outer membrane of mitochondria and catalyzes the $\beta$ oxidation of fatty acids to reduce the concentration of intracellular fatty acids [23]. Additionally, perilipin A located on the surface of lipid droplets in adipocytes prevents lipid hydrolysis of lipid droplets and protects them in adipocytes [24], whereas triglyceride lipase (ATGL) and hormone-sensitive lipase (HSL) are important to the process of fat hydrolysis and represent $95 \%$ of the activity of lipid-hydrolytic enzymes in adipose tissue [25]. All of these factors play key roles in lipid metabolism.

3T3-L1 preadipocytes are typical cells that can be specifically induced to differentiate into adipocytes and frequently used in lipid metabolism research. In this study, we explored the effects of bilobalide on adipogenesis and AMPK signaling in 3T3-L1 cells.

\section{Results}

\subsection{Cell Cytotoxicity of Bilobalide on 3T3-L1 Cells}

A thiazolyl blue tetrazolium bromide (MTT) assay was used to determine the cytotoxicity of bilobalide on both 3T3-L1 preadipocytes and differentiated adipocytes. Following treatment for $24 \mathrm{~h}$, bilobalide at various concentrations did not show an inhibitory effect on 3T3-L1 preadipocyte proliferation but increased the cell viability slightly with statistical significance (Figure 2A), whereas bilobalide treatment exhibited significant cytotoxicity on mature adipocytes in a dose-dependent manner (Figure 2B). Compared with the control group, the cell viability of mature adipocytes significantly decreased to $67 \%$ following treatment with $200 \mu \mathrm{M}$ bilobalide. 


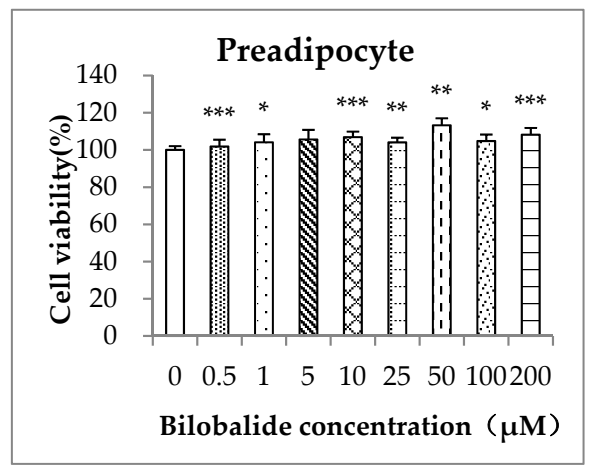

(A)

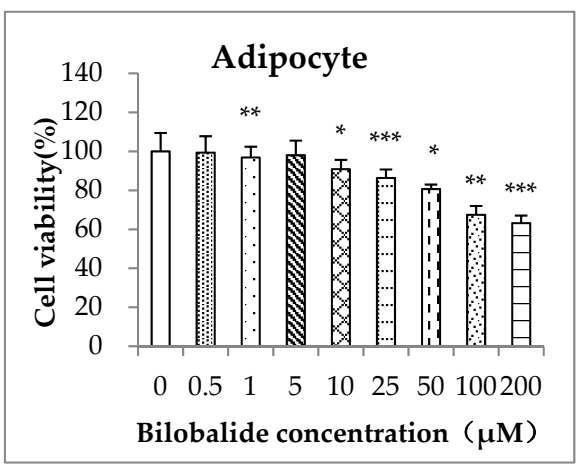

(B)

Figure 2. Cell viability of 3T3-L1 preadipocytes and adipocytes. (A) Preadipocytes and (B) adipocytes were treated with different concentrations $(0-200 \mu \mathrm{M})$ of bilobalide for $24 \mathrm{~h}$. Results are presented as the cell viability as compared with the compound-free group. Data are presented as the mean \pm standard deviation from three independent experiments. ${ }^{*} p<0.05,{ }^{* *} p<0.01,{ }^{* * *} p<0.001$.

\subsection{Bilobalide Inhibits Lipid Accumulation in 3T3-L1 cells}

To evaluate the effect of bilobalide on adipogenesis, 3T3-L1 preadipocytes were treated with bilobalide at various concentrations during the process of adipo-differentiation for 5 days (day 4 to day 8). The intracellular lipid accumulation was evaluated by Oil Red O (ORO) staining. Microscopy showed that $25 \mu \mathrm{M}$ and $100 \mu \mathrm{M}$ bilobalide significantly decreased ORO staining in differentiated 3T3-L1 adipocytes (Figure 3A). We used isopropanol to extract the ORO dye and semi-quantitatively analyzed the absorbance at $510 \mathrm{~nm}$, revealing that $25 \mu \mathrm{M}$ and $100 \mu \mathrm{M}$ bilobalide significantly inhibited the lipid accumulation by $25 \%$ and $39 \%$, respectively, relative to the control group ( $p<0.001$ ) (Figure 3B).

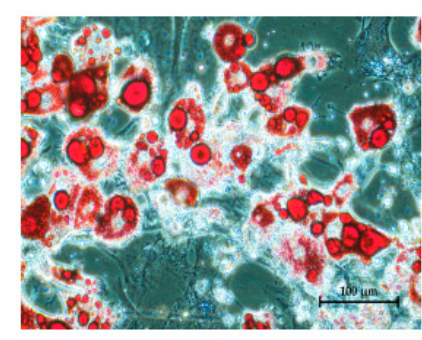

CT 200X

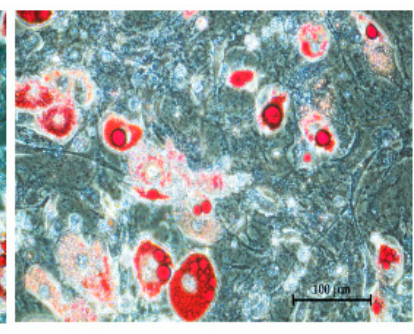

BB $25 \mu \mathrm{M} 200 \mathrm{X}$

(a)

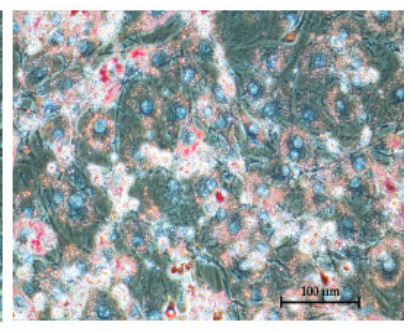

BB $100 \mu \mathrm{M} 200 \mathrm{X}$

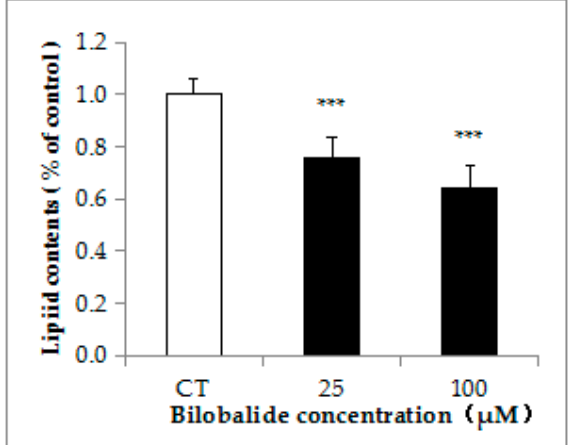

(b)

Figure 3. Effect of bilobalide on intracellular lipid accumulation during adipocyte differentiation. 3T3-L1 preadipocytes were cultured in adipo-differentiation media and treated with 0,25 , or $100 \mu \mathrm{M}$ bilobalide and incubated for 5 days (day 4 to day 8) during differentiation, and staining was conducted using ORO solution. (a) Representative cell images were captured at $200 \times$ magnification. (b) Intracellular lipid accumulation is expressed as a percentage of control values. Data are presented as the mean \pm standard deviation $((n=3))^{*} p<0.05,{ }^{* *} p<0.01,{ }^{* * *} p<0.001$. 


\subsection{Bilobalide Downregulates the Expression of Adipogenic Transcription Factors}

Differentiation-associated lipid accumulation was induced by upregulated levels of several adipogenic transcription factors, including $\mathrm{C} / \mathrm{EBP} \alpha, \operatorname{PPAR} \gamma$, and SREBP-1c. To evaluate the effect of bilobalide on their expression, 3T3-L1 preadipocytes were treated with 0 (control), 25, and $100 \mu \mathrm{M}$ bilobalide during adipo-differentiation from day 4 to day 8 . The results showed that mRNA levels of the three transcription factors were attenuated in a concentration-dependent manner. The $25 \mu \mathrm{M}$ bilobalide decreased the mRNA levels of $P P A R \gamma, C / E B P \alpha$, and SREBP-1c by 30\%, 18\%, and 38\%, respectively, compared to the control groups $(p<0.001)$; and the $100 \mu \mathrm{M}$ bilobalide further decreased them by $57 \%, 38 \%$, and $67 \%$, respectively (Figure $4 \mathrm{~A}, p<0.001$ ). In line with that, the protein expression of PPAR $\gamma, \mathrm{C} / \mathrm{EBP} \alpha$, and SREBP-1c went down steadily with the increasing dose of bilobalide. We observed a reduction of $80 \%, 25 \%$, and $40 \%$, respectively, in their protein levels upon the $100-\mu \mathrm{M}$ bilobalide treatment, as compared with the control groups (Figure 4B).

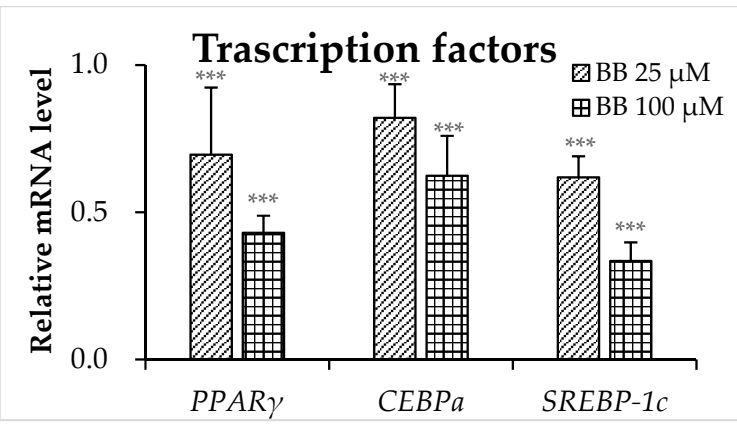

(A)
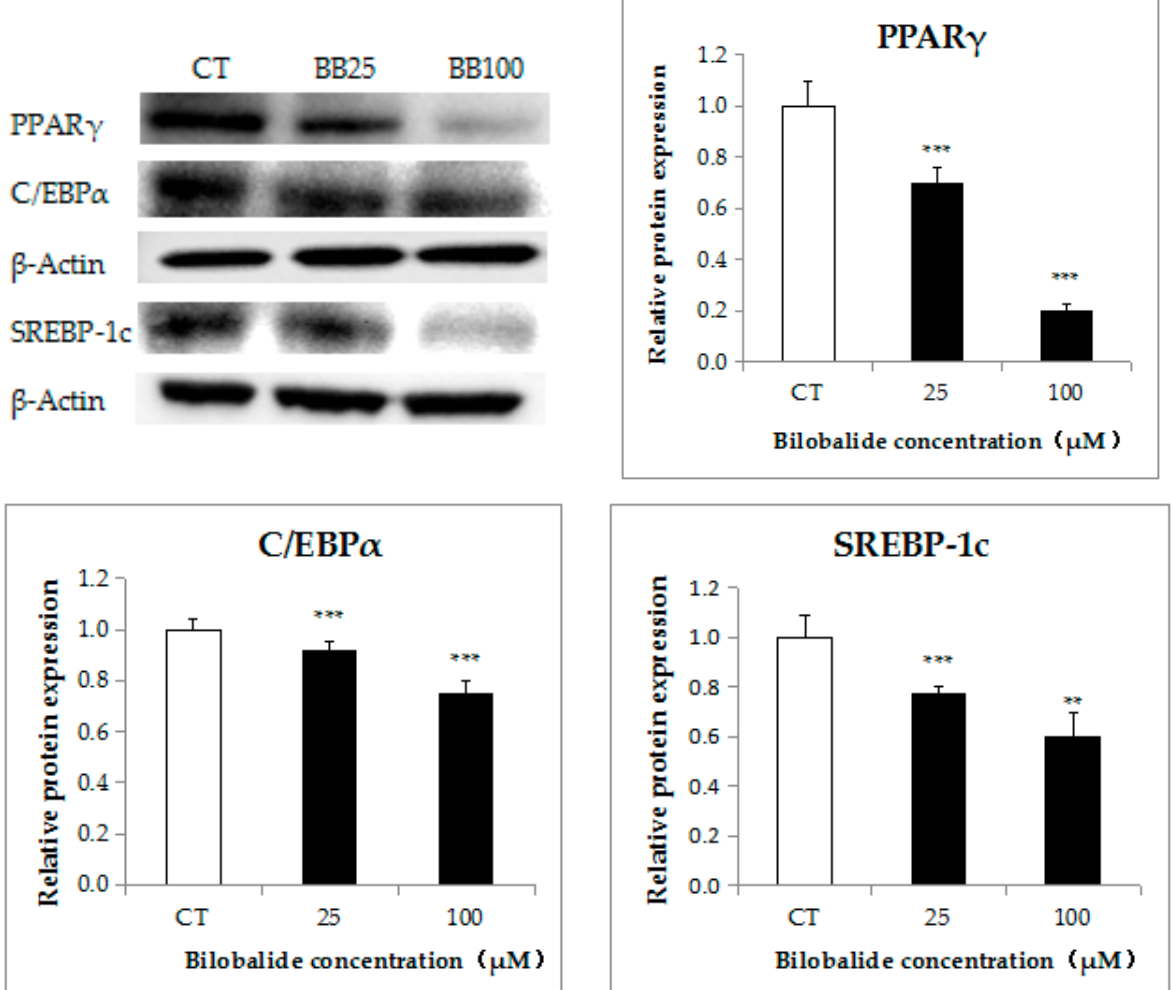

(B)

Figure 4. The effects of different bilobalide concentrations on adipogenic transcription factors. (A) The mRNA expression of PPAR $\gamma, C E B P-\alpha$, and SREBP-1c. (B) Western blot analysis of PPAR $\gamma$, CEBP- $\alpha$, and SREBP-1c protein levels. Histograms show quantification of protein levels according to band intensities. Data are presented as the mean \pm standard deviation $\left((n=3) .{ }^{*} p<0.05,{ }^{* *} p<0.01\right.$, *** $p<0.001$. 


\subsection{The Effect of Bilobalide on the Expression of Adipogenic Genes in Adipocytes}

We then evaluated whether bilobalide could attenuate the expression of several important adipogenesis-related genes, including fatty acid synthase (FASN), perilipin A, and GLUT-4. After the $25-\mu \mathrm{M}$ bilobalide treatment, the mRNA levels of FASN, perilipin A, and GLUT-4 decreased by $61 \%$, $25 \%$, and $83 \%$, respectively, relative to controls (Figure $5 \mathrm{~A}, p<0.001$ ). Although the $100-\mu \mathrm{M}$ bilobalide treatment did not further decrease the transcription levels of those genes, their protein levels were continuously down-regulated with the increasing concentration of bilobalide (Figure 5A). The bilobalide treatment significantly reduced the protein expression levels of FASN and perilipin A by $22 \%(p<0.01)$ and $51 \%(p<0.001)$, respectively, at $25 \mu \mathrm{M}$, and by $37 \%(p<0.05)$ and $91 \%(p<0.001)$, respectively, at $100 \mu \mathrm{M}$. The $28 \%$ reduction in GLUT-4 protein by the $25-\mu \mathrm{M}$ bilobalide was not statistically significant, while the $100-\mu \mathrm{M}$ bilobalide gave rise to a $77 \%$ decrease with statistical significance $(p<0.001)$.

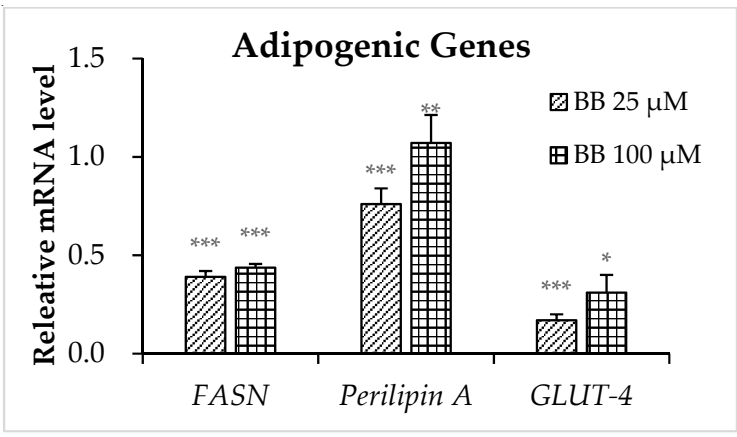

(A)

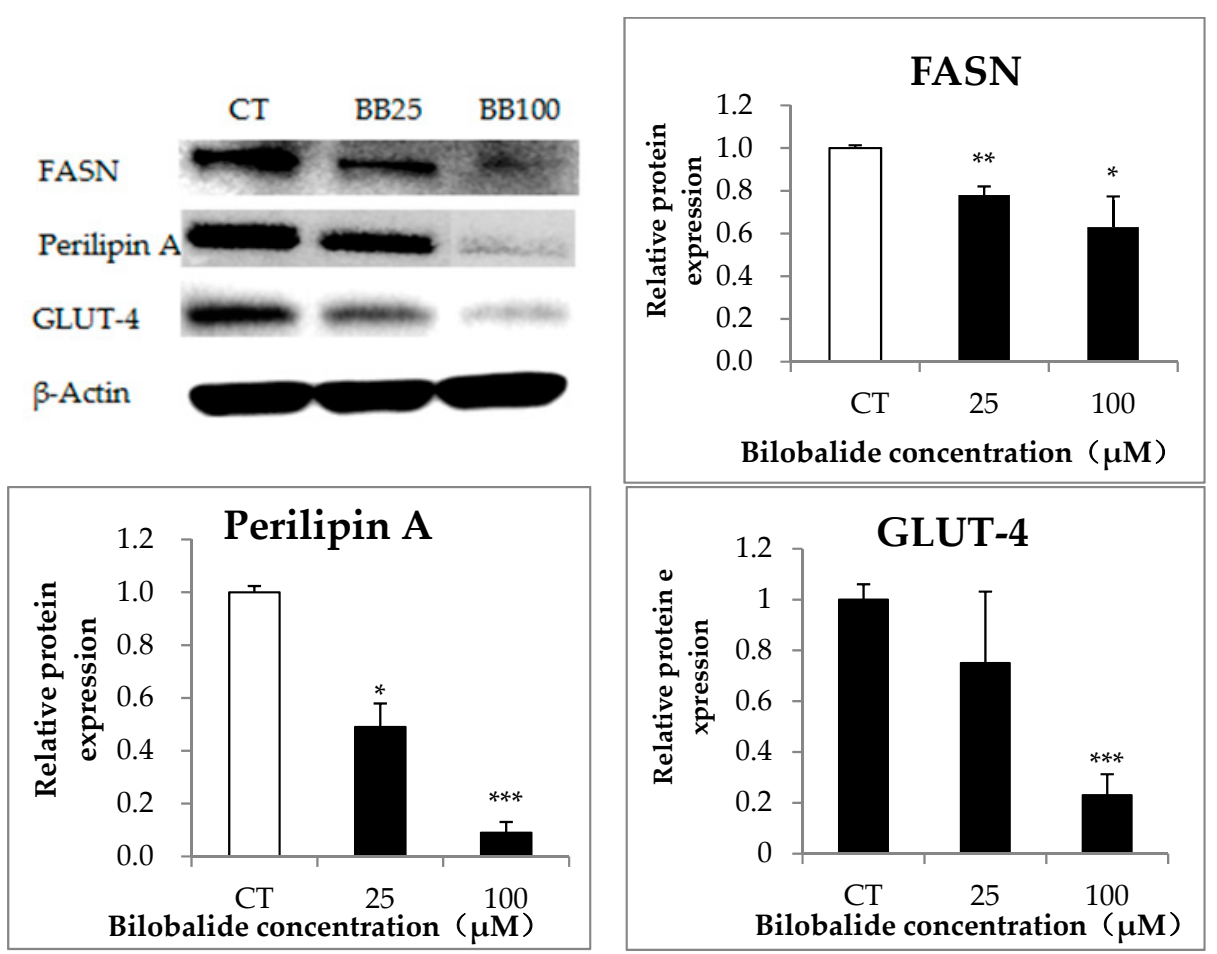

(B)

Figure 5. Effects of different bilobalide concentrations on the expression of adipogenic genes. 3T3-L1 cells were cultured 8 days after initiation of differentiation; cells were treated with 0,25 , or $100 \mu \mathrm{M}$ bilobalide for 5 days during differentiation. (A) The relative mRNA expression of FASN, perilipin A, and GLUT-4 was quantified by qRT-PCR. (B) Western blot was performed to determine protein levels of the same molecules. Histograms showed quantified levels of band intensities for each protein using Image Lab software. Data represent the mean \pm standard deviation $(\mathrm{n}=3) .{ }^{*} p<0.05,{ }^{* *} p<0.01$, *** $p<0.001$. 


\subsection{The Effect of Bilobalide on the Expression of Lipolytic Genes in 3T3-L1 Cells}

We found that ATGL mRNA levels were up-regulated by 165\% $(p<0.001)$ and 54\% $(p<0.01)$ following the $25-\mu \mathrm{M}$ and 100- $\mu \mathrm{M}$ bilobalide treatment, respectively, relative to controls, whereas CPT1 $\alpha$ mRNA levels showed only a slight increase $(\sim 20 \%)$ at both concentrations $(p<0.05)$ (Figure 6A). Additionally, the protein levels of ATGL in the treatment groups were also increased by $47 \%(p<0.01$, $25 \mu \mathrm{M})$ and $57 \%(p<0.001,100 \mu \mathrm{M})$ as compared with that of the control groups, while the protein expression of CPT1 $\alpha$ showed an upward trend with no statistical significance after the bilobalide treatment. Furthermore, the ratios of the phosphorylated HSL (the activated form) to the total HSL were raised by the bilobalide treatment and the $25-\mu \mathrm{M}$ bilobalide treatment led to the optimal increase (Figure 6B, $p<0.001$ ). These results indicated that bilobalide promoted the expression of genes involved in lipolysis.
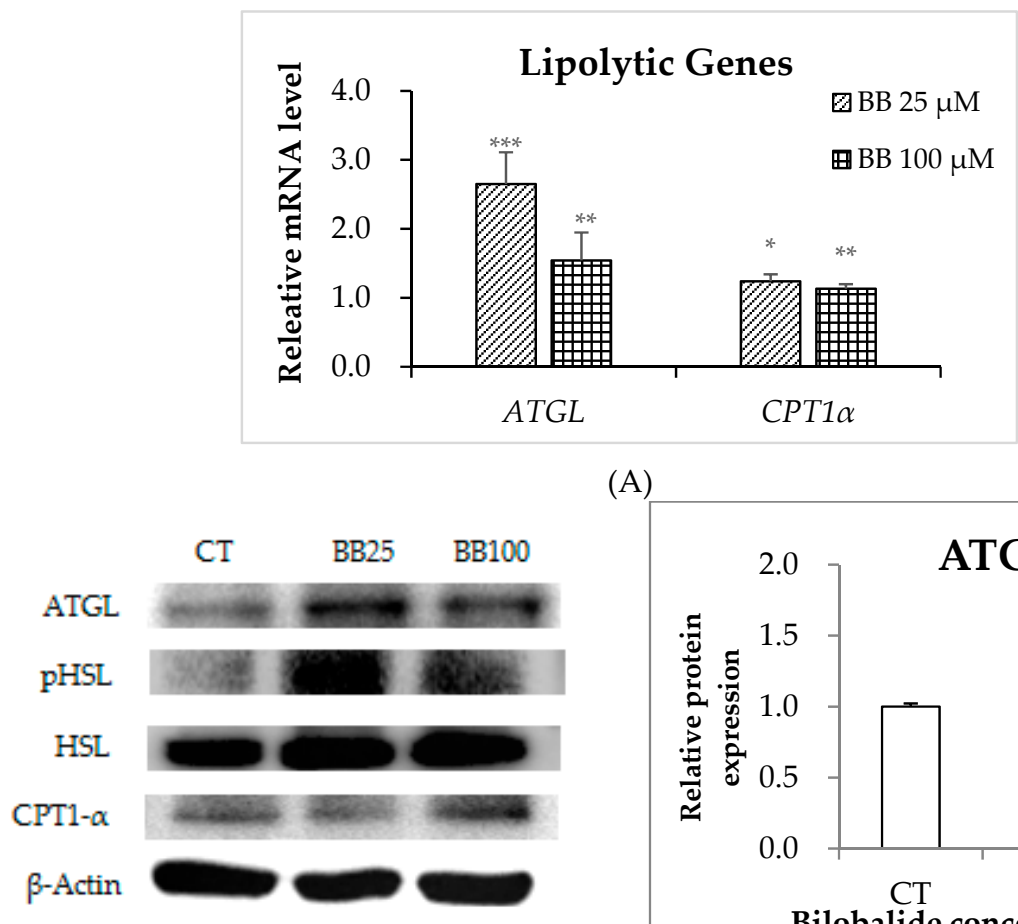

(A)
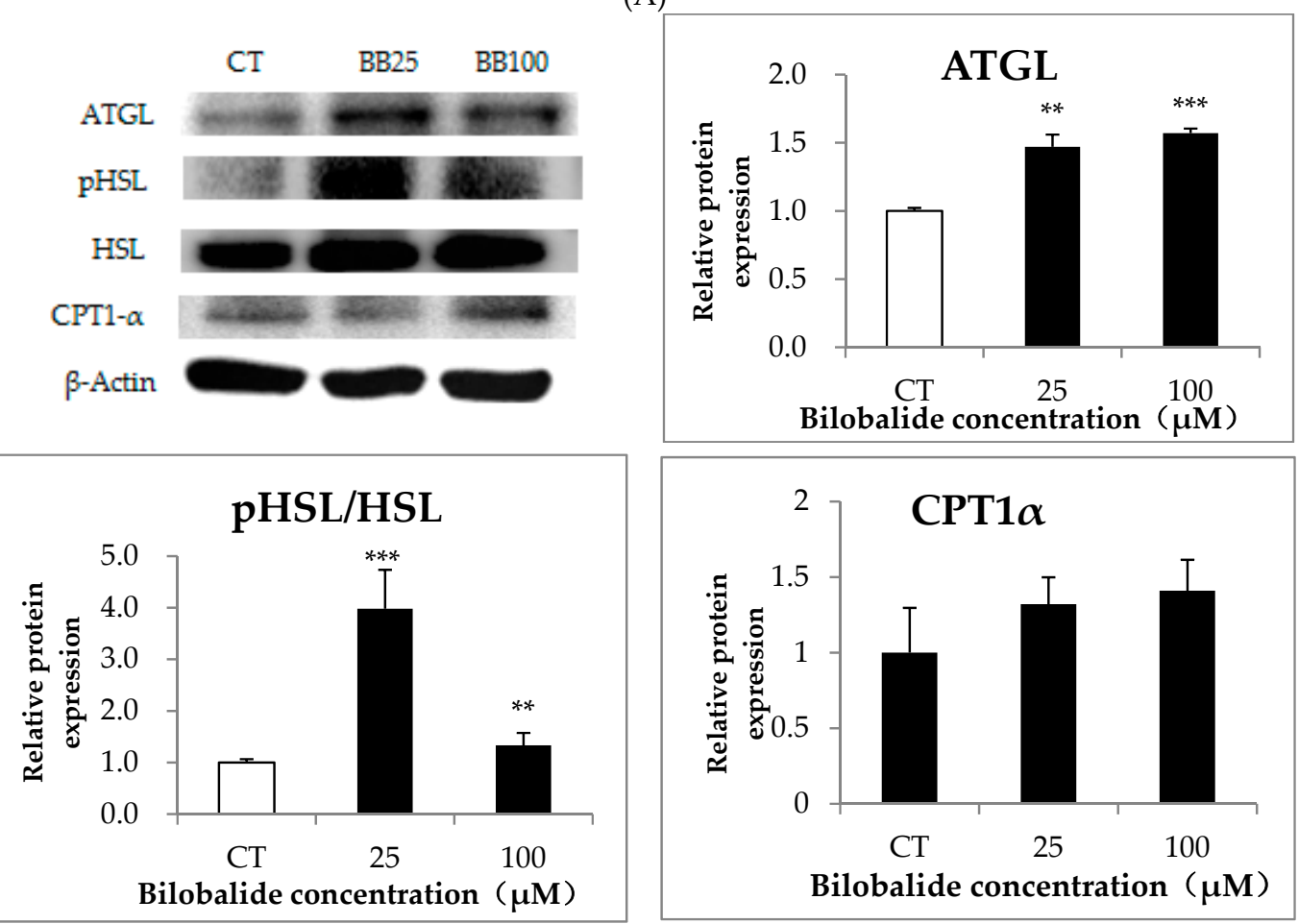

(B)

Figure 6. Effects of different bilobalide concentrations on the expression of lipolytic genes. 3T3-L1 cells were differentiated to adipocytes and treated with 0,25 , or $100 \mu \mathrm{M}$ bilobalide for $24 \mathrm{~h}$. (A) The relative mRNA expression of ATGL, HSL, and CPT1 $\alpha$ was quantified by qRT-PCR. (B) Western blot was performed to determine the protein levels of ATGL, HSL, phosphorylated HSL, and CPT1 $\alpha$. Protein bands were quantified by Image Lab software, and histograms represent quantified band intensities for each protein. Data represent the mean \pm standard deviation $(n=3) .{ }^{*} p<0.05,{ }^{* *} p<0.01,{ }^{* * *} p<0.001$. 


\subsection{Bilobalide Activates AMPK Signaling}

Western Blot results indicated that the phosphorylation of AMPK and ACC1 was significantly enhanced by bilobalide at both $25 \mu \mathrm{M}$ and $100 \mu \mathrm{M}$, with a 10-fold increase in the ratio of the phosphorylated ACC1 to the total ACC1 upon the $25-\mu \mathrm{M}$ bilobalide treatment and a $158 \%$ increase in the ratio of the phosphorylated AMPK to the total AMPK upon the $100-\mu \mathrm{M}$ bilobalide treatment (Figure 7A, $p<0.05$ ). Additionally, enzyme-linked immunosorbent assay (ELISA) results showed similar relative AMPK activity at both bilobalide concentrations to that elicited by the treatment with 5-aminoimidazole-4-carboxamide ribonucleotide (AICAR; an activator of AMPK signaling). Furthermore, we confirmed that the treatment of compound C (an inhibitor of AMPK signaling) significantly attenuated the relative AMPK activity, whereas bilobalide at either concentration rescued the compound C-mediated inhibition $(p<0.001)$ (Figure 7B).

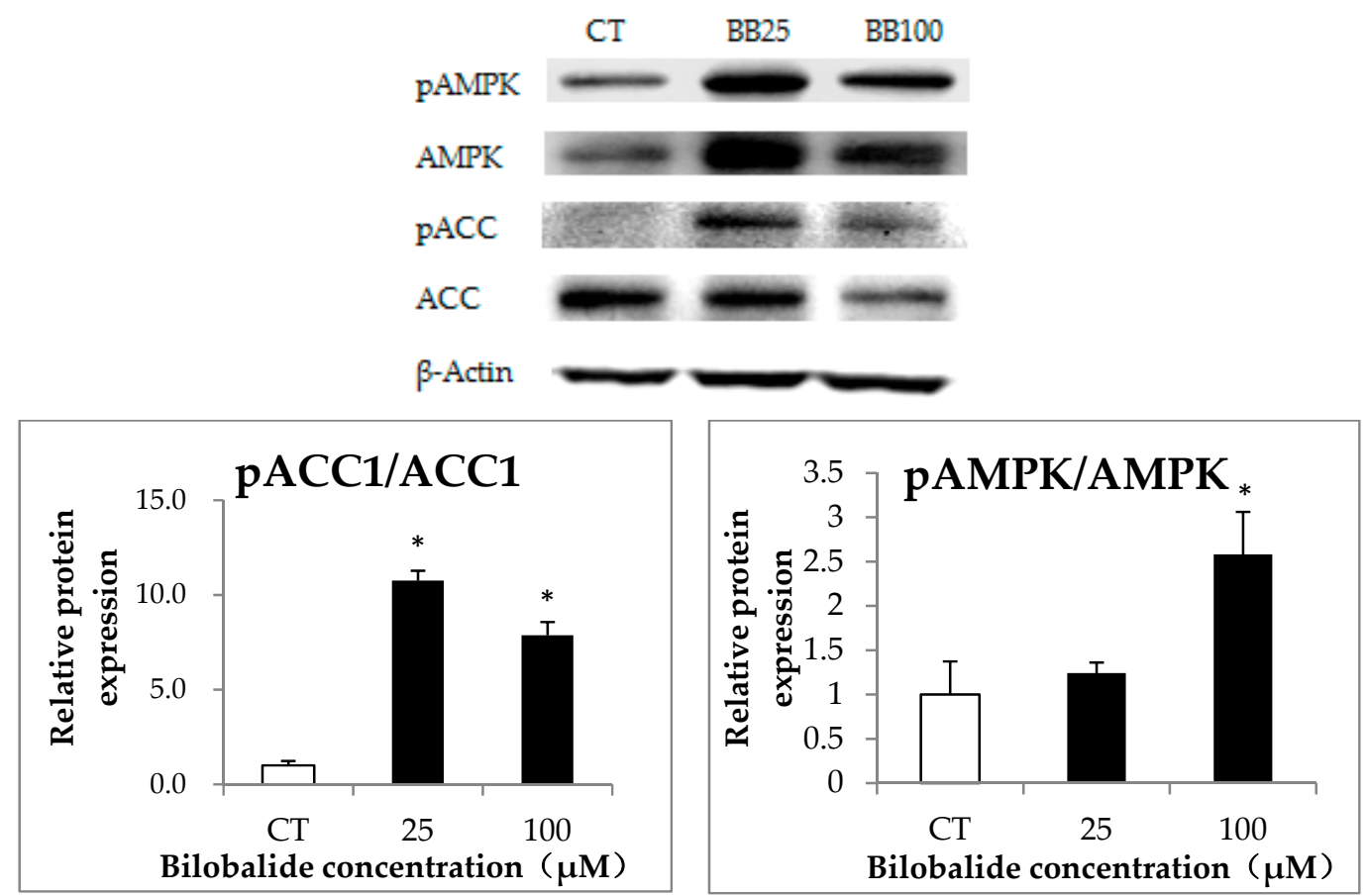

(A)

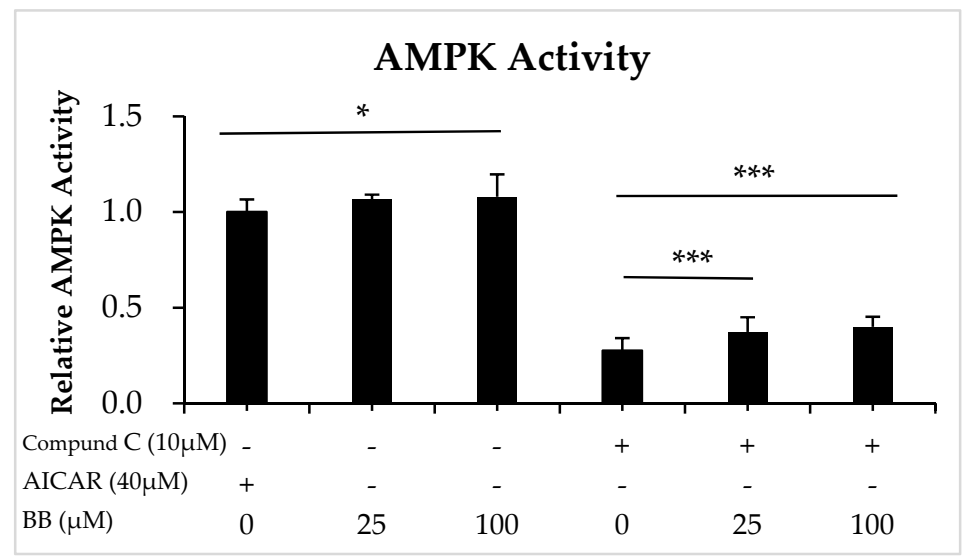

(B)

Figure 7. Bilobalide promotes AMPK phosphorylation and signaling. (A) Total protein was extracted from differentiated adipocytes, and changes in ACC1 and AMPK phosphorylation were determined. (B) Relative AMPK activity from ELISA assay following treatment with AICAR $(40 \mu \mathrm{M})$, compound $\mathrm{C}(10 \mu \mathrm{M})$, and $25 \mu \mathrm{M}$ and $100 \mu \mathrm{M}$ bilobalide presented as a percentage relative to the control group. $* p<0.05,{ }^{* * *} p<0.001$. 


\section{Discussion}

Excessive eating and a sedentary lifestyle resulting in energy imbalance eventually leads to obesity, which is characterized by hypertrophy and hyperplasia of adipose tissue. Adipose tissue comprises adipocytes, preadipocytes, fibroblasts, vascular endothelial cells, and macrophages. Differentiation of preadipocytes into adipocytes (adipogenesis) is regulated by complex processes, which include the expression of adipogenic genes and activation of specific transcriptional factors and lipogenic enzymes. Because adipogenesis plays a key role in the development of obesity, it represents a target for obesity treatment, with current research focused on the discovery of safe and novel natural compounds capable of alleviating this process and to be used as alternative anti-obesity treatments [26-28].

Ginkgo biloba extract (GBE) reportedly exhibits extensive pharmaceutical activities [29]. Studies show that GBE can ameliorate lipid metabolism in high-fat diet-induced obese, diabetic, or non-alcoholic fatty liver disease animal models [30,31]. Additionally, several flavonoid components in GBE, including quercetin, kaempferol, and isorhamnetin, are widely found in fruits and vegetables and reportedly exhibit beneficial effects toward improving lipid profiles [32-34]. Ginkgolide A is non-toxic at high concentrations in hepatocytes, which inhibits lipid accumulation and displays hepatoprotective efficacy by inducing cellular lipoapoptosis and inhibiting cellular inflammation [15]. Ginkgolide $C$ increases the expression of lipolytic enzymes, reduces adipogenic gene expression, and inhibits lipid accumulation in 3T3-L1 adipocytes [35].

Due to the structural similarity of bilobalide to ginkgolides, we hypothesized that bilobalide might also exert a regulatory effect on lipid metabolism. Here, we investigated the effect of bilobalide on lipid metabolism in 3T3-L1 cells. We found that bilobalide treatment reduced the accumulation of lipid droplets, inhibited the expression of adipogenic transcription factors and enzymes, and promoted AMPK phosphorylation to increase lipolysis in differentiated adipocytes.

AMPK is a metabolic energy sensor that plays a key role in regulating energy homeostasis [36,37]. Phosphorylation of AMPK stimulates substrate phosphorylation and inactivates the cytosolic isoform of ACC1 that provides malonyl-CoA the substrate necessary for fatty acid biosynthesis, thereby inhibiting fatty acid synthesis $[38,39]$.

In the present study, we observed that bilobalide treatment promoted AMPK and ACC1 phosphorylation (Figure 7A). Our ELISA results verified that bilobalide promoted the relative AMPK activity to a degree similar to that elicited by 5 -amino-4-imidazole carboxamide riboside (AICAR) $(p<0.05)$ (Figure 7B). Additionally, the AMPK phosphorylation up-regulated ATGL expression and phosphorylation of HSL (Figure 6). ATGL catalyzes the first step of triglycerol degradation to diacylglycerol and one molecule of free fatty acid [40], and phosphorylated HSL hydrolyzes diacylglycerol into monoacylglycerol and one molecule of fatty acid [41], with both of these activities enhancing hydrolysis of intracellular triglycerides [42]. Moreover, CPT1 $\alpha$ activity is regulated by AMPK, which promotes CPT1 $\alpha$ expression and accelerates the rate of fatty acid $\beta$ oxidation in mitochondria [43]. Furthermore, SREBP-1c is a lipogenic transcription factor directly phosphorylated by AMPK [44] and is involved in inducing the expression of ACC1 and FASN to stimulate fatty acid synthesis in cells [45]. Several studies demonstrated that phosphorylation of AMPK suppressed the ACC1 and FASN expression [46-48]. In the present study, we showed that bilobalide significantly suppressed the expression of adipogenic factors, such as SREBP-1c, PPAR $\gamma, C / E B P \alpha, F A S N$, and perilipin A, during differentiation of 3T3-L1 cells. Although it is well established that AMPK activation will improve the translocation of GLUT4 to the cell membrane and improve the insulin sensitivity and whole body glucose homeostasis, a recent report indicated that mice overexpressing GLUT4 in adipocytes (AG4OX) have elevated adipose tissue lipogenesis and enhanced glucose tolerance despite being obese [49]. In accordance with our result of bilobalide treatment down-regulating GLUT4 expression and inhibiting adipogenesis, another study showed that pomegranate polyphenols and urolithin A down-regulated the gene expression of glucose and fatty acid metabolism, such as GLUT4, FABP4, and PPAR $\gamma$, in 3T3-L1 like cells [50]. However, whether the down-regulation of GLUT4 in this study is AMPK-dependent or not requires further investigation. 
Our MTT assay results indicated that bilobalide exhibited a dose-dependent toxicity against mature adipocytes but was non-toxic to preadipocytes. It is reasonable to speculate that bilobalide might trigger apoptosis in mature adipocytes, resulting in decreased adipose tissue. However, this hypothesis needs to be tested in an animal model.

In conclusion, our results demonstrated that bilobalide inhibited lipid accumulation in 3T3-L1 cells, reduced the expression of adipogenic genes, and enhanced lipolytic enzyme activity. Furthermore, our data suggested that AMPK signaling contributed to these effects (Figure 8). These findings represent the first evidence of bilobalide-mediated activation of AMPK signaling and its potential efficacy for the treatment of obesity. Studies are required to clarify the effect of bilobalide on fat accumulation in vivo.

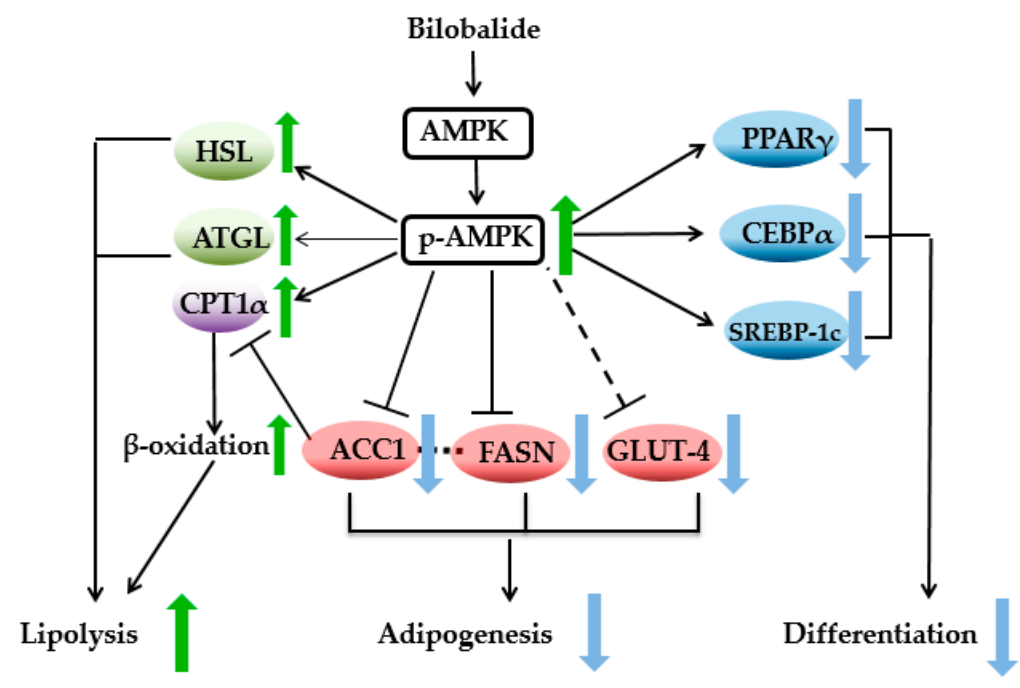

Figure 8. Schematic diagram showing the molecular mechanism of BB decreases lipid accumulation and inhibits obesity by down-regulating multiple transcription factors, inhibiting the synthesis of lipid accumulation proteins, and promoting the expression of lipid-degrading proteins in 3T3-L1 cells.

\section{Materials and Methods}

\subsection{Chemicals and Reagents}

Dulbecco's modified Eagle medium (DMEM), Dulbecco's phosphate-buffered saline (DPBS), fetal bovine serum (FBS), and 0.25\% trypsin were purchased from Gibco (Rockville, MD, USA). Penicillin-streptomycin solution was purchased from Hyclone (Provo, UT, USA). Insulin, dexamethasone (DEX), 3-isobutyl-1-methylxanthine (IBMX), and MTT were obtained from Sigma-Aldrich (St. Louis, MO, USA). 3T3-L1 preadipocytes were purchased from ATCC (Manassas, VA, USA). Bilobalide was obtained from the National Institutes for Food and Drug Control (Beijing, China). Primary antibodies specific for anti-pACC1 (S79), anti-ACC1, anti-FASN, anti-perilipin A, anti-ATGL, anti-C/EBP $\alpha$, anti-PPAR $\gamma$, anti-HSL, anti-pHSL (S563), anti-GLUT-4, anti-CPT-1 $\alpha$, anti-AMPK, and anti-pAMPK (T172) were acquired from Cell Signaling Technology (Danvers, MD, USA). Anti-SREBP-1c was acquired from Abcam (Cambridge, UK). Anti- $\beta$-Actin and goat anti-mouse and goat anti-rabbit IgG secondary antibodies were obtained from Boster Biological Technology (Pleasanton, CA, USA). The AMPK assay kit was purchased from Cell Signaling Technology.

\subsection{Cell Culture}

3T3-L1 preadipocytes were propagated in DMEM (low glucose) supplemented with 10\% FBS and penicillin $(100 \mathrm{U} / \mathrm{mL})$, and streptomycin $(100 \mu \mathrm{g} / \mathrm{mL})$ and maintained in a humidified atmosphere of $5 \%$ $\mathrm{CO}_{2}$ at $37^{\circ} \mathrm{C}$. After reaching confluence, the medium was changed to DMEM (high glucose), and after 2 days (day 0 ), the medium was replaced with adipocyte-differentiation medium I (high-glucose DMEM containing 10\% FBS, penicillin-streptomycin, $0.1 \mu \mathrm{M}$ DEX, $0.5 \mathrm{mM}$ 3-isobutyl-1-methylxanthine, and 
$10 \mu \mathrm{g} / \mathrm{mL}$ insulin). After $72 \mathrm{~h}$ (day 3), the medium was replaced with adipocyte-differentiation medium II (high-glucose DMEM containing 10\% FBS, penicillin-streptomycin, and $10 \mu \mathrm{g} / \mathrm{mL}$ insulin). After 2 or 3 days of culture, the medium was replaced with DMEM containing 10\% FBS and penicillin-streptomycin and cultured until the end of differentiation. Cells were treated with bilobalide at various concentrations from day 3 until the end of the differentiation.

\subsection{MTT Assay}

3T3-L1 cells were distributed in 96-well plates, and after reaching confluence or undergoing complete cell differentiation, the medium was replaced with $100 \mu \mathrm{L}$ bilobalide at different concentrations and incubated for $24 \mathrm{~h}$. Preadipocytes were treated with DMEM containing 10\% FBS and corresponding concentrations of bilobalide, whereas adipocytes were treated with DMEM containing $1 \%$ FBS and corresponding concentrations of bilobalide. The culture medium was replaced with $50 \mu \mathrm{L}$ of fresh culture medium containing $1 \mathrm{mg} / \mathrm{mL}$ MTT working solution, and after $4 \mathrm{~h}$, formazan was dissolved in $100 \%$ dimethyl sulfoxide, and the absorbance was measured at $595 \mathrm{~nm}$. Cell survivability (\%) was expressed as the percentage of viable cells relative to the control.

\subsection{ORO Staining}

After differentiation, 3T3-L1 cells were washed twice with DPBS (pH 7.4), fixed with $10 \%$ formaldehyde for $1 \mathrm{~h}$ at room temperature, and stained with freshly prepared ORO working solution $(0.3 \mathrm{mg} / \mathrm{mL})$ at room temperature for $90 \mathrm{~min}$, followed by two washes with distilled water. Images were obtained using a microscope (Leica DMIL LED; Leica, Frankfurt, Germany), and stained oil droplets were dissolved in isopropanol and quantified at $490 \mathrm{~nm}$ using a spectrophotometer (FilterMAX F5; Molecular Devices, USA).

\subsection{Quantification of the Expression of Adipogenic Genes in 3T3-L1 Cells}

Total RNA was extracted from 3T3-L1 cells using a MiniBEST universal RNA extraction kit (Takara Bio, Shiga, Japan). RNA concentrations were quantified using a NanoDrop ND-1000 Micro spectrophotometer (NanoDrop Technologies, Wilmington, DE, USA), and reverse transcription was performed using $1 \mu \mathrm{g}$ of total RNA and PrimeScript RT master mix (Takara) according to the manufacturer's instructions. qRT-PCR was performed using a SYBR Premix Ex Taq II kit (Takara), with the amplification reaction monitored on a qPCR thermal cycler (Step One Plus; Applied Biosystems, Foster City, CA, USA). Relative expression was determined using the $2^{-\Delta \Delta C T}$ method, with levels normalized against those of $18 \mathrm{~S}$ rRNA or the housekeeping gene glyceraldehyde 3-phosphate dehydrogenase. Values are presented as fold changes compared to the control. The specific primers used in this study are listed in Table 1.

\subsection{Western Blot}

3T3-L1 adipocytes treated with the indicated concentrations of bilobalide during differentiation (days 3-9) were collected and lysed in radioimmunoprecipitation assay buffer (Biosharp, Anhui, China) containing $50 \mathrm{mM}$ Tris ( $\mathrm{pH}$ 7.4), $150 \mathrm{mM} \mathrm{NaCl}, 1 \%$ Triton X-100, $1 \%$ sodium deoxycholate, $0.1 \%$ SDS, a protease-inhibitor cocktail (Leupetin, PepstatinA, Aprotinin, E-64; Solarbio, Beijing, China), and a phosphatase-inhibitor cocktail (containing $25 \mu \mathrm{M}(-)$-p-bromotetramisole oxalate, $500 \mu \mathrm{M}$ cantharidin, and $1 \mu \mathrm{M}$ calyculin A; Beyotime, Shanghai, China). Total cellular proteins (30 $\mu \mathrm{g})$ were separated by $10 \%$ SDS polyacrylamide gel electrophoresis (PAGE) or using $4 \%$ to $12 \%$ pre-cast SDS-PAGE gels (Bio-Rad, Hercules, CA, USA) and transferred onto nitrocellulose membranes ( $0.45 \mu \mathrm{m}$; Millipore, Bedford, MA, USA). The membranes were incubated overnight at $4{ }^{\circ} \mathrm{C}$ with primary antibodies, followed by three washes Tris-buffered saline containing 0.1\% Tween-20 (Biosharp, HeFei, China), probing with horseradish peroxidase-conjugated secondary antibody, and development using enhanced chemiluminescence (ECL; Bio-Rad). The membranes were washed briefly with Tris-buffered saline (10 mM Tris- $\mathrm{Cl}$ and $150 \mathrm{mM} \mathrm{NaCl}$; pH 7.5) supplemented with $0.05 \%$ Tween-20 (TBST), followed by 
blocking with TBST containing $5 \%(\mathrm{w} / \mathrm{v})$ nonfat dried milk or $5 \%$ bovine serum albumin according to protocol associated with the respective primary antibody. Immunoreactive proteins were visualized using an ECL reagent (ECL Substrate; BioRad), and signals were quantified by densitometry with Image Lab software (BioRad).

Table 1. Primers used for qRT-PCR.

\begin{tabular}{|c|c|c|}
\hline Name & GenBank No. & Primer Sequence $\left(5^{\prime}-3^{\prime}\right)$ \\
\hline \multirow{2}{*}{ PPAR $\gamma$} & \multirow{2}{*}{ NM_001308354.1 } & F: AGGCCGAGAAGGAGAAGCTGTTG \\
\hline & & R: TGGCCACCTCTTTGCTCTGCTC \\
\hline \multirow{2}{*}{$C / E B P \alpha$} & \multirow{2}{*}{ NM_001308354.1 } & F: GCCCCCGTGAGAAAAATGAAG \\
\hline & & R: GAGGTGCGAAAAGCAAGGGA \\
\hline \multirow{2}{*}{ FASN } & \multirow{2}{*}{ NM_007988.3 } & F: ATTCGGTGTATCCTGCTGTC \\
\hline & & R: GCTTGTCCTGCTCTAACTGG \\
\hline \multirow{2}{*}{$S R E B P-1 c$} & \multirow{2}{*}{ NM_001278601 } & F: TGGACTACTAGTGTTGGCCTGCTT \\
\hline & & R: ATCCAGGTCAGCTTGTTTGCGATG \\
\hline \multirow{2}{*}{ GLUT-4 } & \multirow{2}{*}{ NM_009204 } & F: AGCCTCTGATCATCGCAGTG \\
\hline & & R: ACCGAGACCAACGTGAAGAC \\
\hline \multirow{2}{*}{ ATGL } & \multirow{2}{*}{ NM_001163689 } & F: GGTTAGAGTTGCTCAGCCGT \\
\hline & & R: ACATGAGGAGCGGATGTGTG \\
\hline \multirow{2}{*}{ CPT1 $\alpha$} & \multirow{2}{*}{ NM_013495 } & F: GGGCTTGGTAGTCAAAGGCT \\
\hline & & R: TGCCTGTGTCAGTATGCCTG \\
\hline \multirow{2}{*}{ Perilipin A } & \multirow{2}{*}{ NM_001113471.1 } & F: CACTCTCTGGCCATGTGGA \\
\hline & & R: AGAGGCTGCCAGGTTGTG \\
\hline \multirow{2}{*}{ 18S rRNA } & \multirow{2}{*}{ NR_003278.3 } & F: ATGCGGCGGCGTTATTCC \\
\hline & & R: CTGTCAATCCTGTCCGTGTCC \\
\hline \multirow{2}{*}{ GAPDH } & \multirow{2}{*}{ XM_029476871.1 } & F: CAGGTTGTCTCCTGCGACTT \\
\hline & & R: TATGGGGGTCTGGGATGGAA \\
\hline
\end{tabular}

\subsection{AMPK Activity Assay}

AMPK activity was determined using an AMPK kinase assay kit (Cell Signaling Technology) according to the manufacturer's instructions. 3T3-L1 adipocytes were either incubated with $25 \mu \mathrm{M}$ or $100 \mu \mathrm{M}$ bilobalide or $40 \mu \mathrm{M}$ AICAR for $24 \mathrm{~h}$ or pretreated with compound $\mathrm{C}(10 \mu \mathrm{M})$ for $1 \mathrm{~h}$, followed by treatment with either bilobalide concentrations for $24 \mathrm{~h}$. Cell lysates were extracted, as described previously, and transferred to the appropriate well containing a specific anti-AMPK primary antibody for overnight incubation at $4{ }^{\circ} \mathrm{C}$. Lysates were then washed four times with wash buffer and incubated with secondary antibodies for $30 \mathrm{~min}$ at $37^{\circ} \mathrm{C}$, followed by the addition of $3,3^{\prime}, 5,5^{\prime}$-tetramethylbenzidine and incubation for $10 \mathrm{~min}$ at $37^{\circ} \mathrm{C}$, replacement with STOP solution, and determination of the absorbance at $450 \mathrm{~nm}$ within $30 \mathrm{~min}$. Relative AMPK activity is presented as a percentage relative to the control.

\subsection{Statistical Analysis}

Values are expressed as the mean \pm standard deviation. Significant differences between experiments performed at the same concentrations in treatment groups were determined using a Student's $t$ test (two-tailed).

Author Contributions: Conceptualization, S.B. and F.C.; methodology, S.B., Q.X., and C.Y.Y.; analysis, C.Y.Y. and Q.X.; writing-original draft preparation, C.Y.Y. and Q.X.; writing-review and editing, S.B. and Y.C.; supervision, S.B. and F.C.; funding acquisition, S.B., Y.C. and F.C.

Funding: This research was funded by the National Key Research and Development Program of China (Grant No. 2017YFD0601301) and National Natural Science Foundation of China (Grant No. 31770674).

Conflicts of Interest: The authors declare no conflicts of interest. 


\section{References}

1. Palou, A.; Bonet, M.L. Challenges in obesity research. Nutr. Hosp. 2013, 28 (Suppl. 5), 144-153. [PubMed]

2. Seidell, J.C.; Halberstadt, J. The global burden of obesity and the challenges of prevention. Ann. Nutr. Metab. 2015, 66 (Suppl. 2), 7-12. [CrossRef]

3. Gonzalez-Muniesa, P.; Martinez-Gonzalez, M.A.; Hu, F.B.; Despres, J.P.; Matsuzawa, Y.; Loos, R.J.F.; Moreno, L.A.; Bray, G.A.; Martinez, J.A. Obesity. Nat. Rev. Dis. Primers 2017, 3, 17034. [CrossRef] [PubMed]

4. Gregg, E.W.; Shaw, J.E. Global Health Effects of Overweight and Obesity. N. Engl. J. Med. 2017, 377, 80-81. [CrossRef] [PubMed]

5. Ginsberg, H.N.; MacCallum, P.R. The obesity, metabolic syndrome, and type 2 diabetes mellitus pandemic: Part I. Increased cardiovascular disease risk and the importance of atherogenic dyslipidemia in persons with the metabolic syndrome and type 2 diabetes mellitus. J. Cardiometabolic Syndr. 2009, 4, 113-119. [CrossRef] [PubMed]

6. Garg, S.K.; Maurer, H.; Reed, K.; Selagamsetty, R. Diabetes and cancer: Two diseases with obesity as a common risk factor. Diabetes Obes. Metab. 2014, 16, 97-110. [CrossRef] [PubMed]

7. Smith, M.M.; Minson, C.T. Obesity and adipokines: Effects on sympathetic overactivity. J. Physiol. 2012, 590, 1787-1801. [CrossRef] [PubMed]

8. Fang, X.; Jiang, Y.; Ji, H.; Zhao, L.; Xiao, W.; Wang, Z.; Ding, G. The Synergistic Beneficial Effects of Ginkgo Flavonoid and Coriolus versicolor Polysaccharide for Memory Improvements in a Mouse Model of Dementia. Evid. Based Complementary Altern. Med. eCAM 2015, 2015, 128394. [CrossRef] [PubMed]

9. Wang, J.Q.; Fang, X.Y.; Ge, L.; Cao, F.L.; Zhao, L.G.; Wang, Z.Z.; Xiao, W. Antitumor, antioxidant and anti-inflammatory activities of kaempferol and its corresponding glycosides and the enzymatic preparation of kaempferol. PLoS ONE 2018, 13, e0197563. [CrossRef] [PubMed]

10. Chandrasekaran, K.; Mehrabian, Z.; Spinnewyn, B.; Drieu, K.; Fiskum, G. Neuroprotective effects of bilobalide, a component of the Ginkgo biloba extract (EGb 761), in gerbil global brain ischemia. Brain Res. 2001, 922, 282-292. [CrossRef]

11. Kiewert, C.; Kumar, V.; Hildmann, O.; Rueda, M.; Hartmann, J.; Naik, R.S.; Klein, J. Role of GABAergic antagonism in the neuroprotective effects of bilobalide. Brain Res. 2007, 1128, 70-78. [CrossRef] [PubMed]

12. Liu, M.; Guo, J.; Wang, J.; Zhang, L.; Pang, T.; Liao, H. Bilobalide induces neuronal differentiation of P19 embryonic carcinoma cells via activating Wnt/beta-catenin pathway. Cell. Mol. Neurobiol. 2014, 34, 913-923. [CrossRef] [PubMed]

13. Shi, C.; Wu, F.; Yew, D.T.; Xu, J.; Zhu, Y. Bilobalide prevents apoptosis through activation of the PI3K/Akt pathway in SH-SY5Y cells. Apoptosis Int. J. Program. Cell Death 2010, 15, 715-727. [CrossRef] [PubMed]

14. Zhou, J.M.; Gu, S.S.; Mei, W.H.; Zhou, J.; Wang, Z.Z.; Xiao, W. Ginkgolides and bilobalide protect BV2 microglia cells against OGD/reoxygenation injury by inhibiting TLR2/4 signaling pathways. Cell Stress Chaperones 2016, 21, 1037-1053. [CrossRef] [PubMed]

15. Jeong, H.S.; Kim, K.H.; Lee, I.S.; Park, J.Y.; Kim, Y.; Kim, K.S.; Jang, H.J. Ginkgolide A ameliorates non-alcoholic fatty liver diseases on high fat diet mice. Biomed. Pharmacother. 2017, 88, 625-634. [CrossRef] [PubMed]

16. Huang, W.C.; Chen, Y.L.; Liu, H.C.; Wu, S.J.; Liou, C.J. Ginkgolide C reduced oleic acid-induced lipid accumulation in HepG2 cells. Saudi Pharm. J. 2018, 26, 1178-1184. [CrossRef]

17. Nguyen, M.T.; Csermely, P.; Soti, C. Hsp90 chaperones PPARgamma and regulates differentiation and survival of 3T3-L1 adipocytes. Cell Death Differ. 2013, 20, 1654-1663. [CrossRef] [PubMed]

18. Shao, H.Y.; Hsu, H.Y.; Wu, K.S.; Hee, S.W.; Chuang, L.M.; Yeh, J.I. Prolonged induction activates Cebpalpha independent adipogenesis in NIH/3T3 cells. PLoS ONE 2013, 8, e51459.

19. Ma, C.; Li, G.; He, Y.; Xu, B.; Mi, X.; Wang, H.; Wang, Z. Pronuciferine and nuciferine inhibit lipogenesis in 3T3-L1 adipocytes by activating the AMPK signaling pathway. Life Sci. 2015, 136, 120-125. [CrossRef] [PubMed]

20. Li, Y.; Zhao, X.; Feng, X.; Liu, X.; Deng, C.; Hu, C.H. Berberine Alleviates Olanzapine-Induced Adipogenesis via the AMPKalpha-SREBP Pathway in 3T3-L1 Cells. Int. J. Mol. Sci. 2016, 17, 1865. [CrossRef]

21. Kim, E.J.; Lee, D.H.; Kim, H.J.; Lee, S.J.; Ban, J.O.; Cho, M.C.; Jeong, H.S.; Yang, Y.; Hong, J.T.; Yoon, D.Y. Thiacremonone, a sulfur compound isolated from garlic, attenuates lipid accumulation partially mediated via AMPK activation in 3T3-L1 adipocytes. J. Nutr. Biochem. 2012, 23, 1552-1558. [CrossRef] [PubMed] 
22. Marsh, B.J.; Alm, R.A.; McIntosh, S.R.; James, D.E. Molecular regulation of GLUT-4 targeting in 3T3-L1 adipocytes. J. Cell Biol. 1995, 130, 1081-1091. [CrossRef] [PubMed]

23. Kang, C.; Yijun, L.; Jingtao, D.; Changyu, P.; Wenhua, Y.; Baoan, W.; Fangling, M.; Xianling, W.; Guoqing, Y.; Yiming, M.; et al. Effects of telmisartan on lipid metabolisms and proinflammatory factors secretion of differentiated 3T3-L1 adipocytes. J. Renin Angiotensin Aldosterone Syst. JRAAS 2015, 16, 1061-1068. [CrossRef] [PubMed]

24. Hong, S.W.; Lee, J.; Park, S.E.; Rhee, E.J.; Park, C.Y.; Oh, K.W.; Park, S.W.; Lee, W.Y. Activation of AMP-Activated Protein Kinase Attenuates Tumor Necrosis Factor-alpha-Induced Lipolysis via Protection of Perilipin in 3T3-L1 Adipocytes. Endocrinol. Metab. 2014, 29, 553-560. [CrossRef] [PubMed]

25. Kim, S.O.; Sakchaisri, K.; Asami, Y.; Ryoo, I.J.; Choo, S.J.; Yoo, I.D.; Soung, N.K.; Kim, Y.S.; Jang, J.H.; Kim, B.Y.; et al. Illudins C2 and C3 stimulate lipolysis in 3T3-L1 adipocytes and suppress adipogenesis in 3T3-L1 preadipocytes. J. Nat. Prod. 2014, 77, 744-750. [CrossRef] [PubMed]

26. Ahn, J.; Lee, H.; Kim, S.; Ha, T. Curcumin-induced suppression of adipogenic differentiation is accompanied by activation of Wnt/beta-catenin signaling. Am. J. Physiol. Cell Physiol. 2010, 298, C1510-C1516. [CrossRef] [PubMed]

27. Chen, T.X.; Cheng, X.Y.; Wang, Y.; Yin, W. Toosendanin inhibits adipogenesis by activating Wnt/beta-catenin signaling. Sci. Rep. 2018, 8, 4626. [CrossRef] [PubMed]

28. Choe, W.K.; Kang, B.T.; Kim, S.O. Water-extracted plum (Prunus salicina L. cv. Soldam) attenuates adipogenesis in murine 3T3-L1 adipocyte cells through the PI3K/Akt signaling pathway. Exp. Ther. Med. 2018, 15, 1608-1615. [PubMed]

29. Wu, Z.; Zhang, J.D.; Gu, X.; Zhang, X.X.; Shi, S.M.; Liu, C. Effects of the extract of Ginkgo biloba on the differentiation of bone marrow mesenchymal stem cells in vitro. Am. J. Transl. Res. 2016, 8, 3032-3040. [PubMed]

30. Banin, R.M.; Hirata, B.K.S.; Andrade, I.S.; Zemdegs, J.C.S.; Clemente, A.P.G.; Dornellas, A.P.S.; Boldarine, V.T.; Estadella, D.; Albuquerque, K.T.; Oyama, L.M.; et al. Beneficial effects of Ginkgo biloba extract on insulin signaling cascade, dyslipidemia, and body adiposity of diet-induced obese rats. Braz. J. Med. Biol. Res. 2014, 47, 780-788. [CrossRef]

31. Wei, T.; Xiong, F.F.; Wang, S.D.; Wang, K.; Zhang, Y.Y.; Zhang, Q.H. Flavonoid ingredients of Ginkgo biloba leaf extract regulate lipid metabolism through Sp1-mediated carnitine palmitoyltranferase 1A up-regulation. J. Biomed. Sci. 2014, 21, 87. [CrossRef] [PubMed]

32. Lee, M.S.; Kim, Y. Effects of Isorhamnetin on Adipocyte Mitochondrial Biogenesis and AMPK Activation. Molecules 2018, 23, 1853. [CrossRef] [PubMed]

33. Lee, Y.J.; Choi, H.S.; Seo, M.J.; Jeon, H.J.; Kim, K.J.; Lee, B.Y. Kaempferol suppresses lipid accumulation by inhibiting early adipogenesis in 3T3-L1 cells and zebrafish. Food Funct. 2015, 6, 2824-2833. [CrossRef] [PubMed]

34. Xu, M.L.; Hu, J.J.; Zhao, W.W.; Gao, X.J.; Jiang, C.H.; Liu, K.; Liu, B.L.; Huang, F. Quercetin differently regulates insulin-mediated glucose transporter 4 translocation under basal and inflammatory conditions in adipocytes. Mol. Nutr. Food Res. 2014, 58, 931-941. [CrossRef] [PubMed]

35. Liou, C.J.; Lai, X.Y.; Chen, Y.L.; Wang, C.L.; Wei, C.H.; Huang, W.C. Ginkgolide C Suppresses Adipogenesis in 3T3-L1 Adipocytes via the AMPK Signaling Pathway. Evid. Based Complementary Altern. Med. eCAM 2015, 2015, 298635. [CrossRef] [PubMed]

36. Mihaylova, M.M.; Shaw, R.J. The AMPK signalling pathway coordinates cell growth, autophagy and metabolism. Nat. Cell Biol. 2011, 13, 1016-1023. [CrossRef] [PubMed]

37. Zhang, B.B.; Zhou, G.C.; Li, C. AMPK: An Emerging Drug Target for Diabetes and the Metabolic Syndrome. Cell Metab. 2009, 9, 407-416. [CrossRef] [PubMed]

38. Davies, S.P.; Carling, D.; Munday, M.R.; Hardie, D.G. Diurnal rhythm of phosphorylation of rat liver acetyl-CoA carboxylase by the AMP-activated protein kinase, demonstrated using freeze-clamping. Effects of high fat diets. Eur. J. Biochem. 1992, 203, 615-623. [CrossRef] [PubMed]

39. He, Z.; Peng, Y.; Duan, W.; Tian, Y.; Zhang, J.; Hu, T.; Cai, Y.; Feng, Y.; Li, G. Aspirin regulates hepatocellular lipid metabolism by activating AMPK signaling pathway. J. Toxicol. Sci. 2015, 40, 127-136. [CrossRef] [PubMed]

40. Young, S.G.; Zechner, R. Biochemistry and pathophysiology of intravascular and intracellular lipolysis. Genes Dev. 2013, 27, 459-484. [CrossRef] [PubMed] 
41. Fruhbeck, G.; Mendez-Gimenez, L.; Fernandez-Formoso, J.A.; Fernandez, S.; Rodriguez, A. Regulation of adipocyte lipolysis. Nutr. Res. Rev. 2014, 27, 63-93. [CrossRef] [PubMed]

42. Wu, Y.L.; Zhou, F.; Jiang, H.T.; Wang, Z.J.; Hua, C.; Zhang, Y.S. Chicory (Cichorium intybus L.) polysaccharides attenuate high-fat diet induced non-alcoholic fatty liver disease via AMPK activation. Int. J. Biol. Macromol. 2018, 118, 886-895. [CrossRef] [PubMed]

43. Yu, H.Y.; Zhang, M.L.; Ma, Y.Q.; Lu, J.X.; Pan, J.M.; Pan, P.; Chen, H.B.; Jia, W.P. 5-ALA ameliorates hepatic steatosis through AMPK signaling pathway. J. Mol. Endocrinol. 2017, 59, 121-128. [CrossRef]

44. Porstmann, T.; Santos, C.R.; Griffiths, B.; Cully, M.; Wu, M.; Leevers, S.; Griffiths, J.R.; Chung, Y.L.; Schulze, A. SREBP activity is regulated by mTORC1 and contributes to Akt-dependent cell growth. Cell Metab. 2008, 8, 224-236. [CrossRef] [PubMed]

45. Li, Y.; Xu, S.; Mihaylova, M.M.; Zheng, B.; Hou, X.; Jiang, B.; Park, O.; Luo, Z.; Lefai, E.; Shyy, J.Y.; et al. AMPK phosphorylates and inhibits SREBP activity to attenuate hepatic steatosis and atherosclerosis in diet-induced insulin-resistant mice. Cell Metab. 2011, 13, 376-388. [CrossRef] [PubMed]

46. Park, Y.K.; Obiang-Obounou, B.W.; Lee, K.B.; Choi, J.S.; Jang, B.C. AZD1208, a pan-Pim kinase inhibitor, inhibits adipogenesis and induces lipolysis in 3T3-L1 adipocytes. J. Cell. Mol. Med. 2018, 22, 2488-2497. [CrossRef] [PubMed]

47. Zhang, J.; Zhang, S.D.; Wang, P.; Guo, N.; Wang, W.; Yao, L.P.; Yang, Q.; Efferth, T.; Jiao, J.; Fu, Y.J. Pinolenic acid ameliorates oleic acid-induced lipogenesis and oxidative stress via AMPK/SIRT1 signaling pathway in HepG2 cells. Eur. J. Pharmacol. 2019, 861, 172618. [CrossRef] [PubMed]

48. Yang, J.Y.; Shi, Z.H.; Ma, W.; Tao, D.Q.; Liu, S.; Chen, L.; Zhou, X.L. Effect of Fuzi Lizhong decoction in reducing liver injury of rats with non-alcoholic fatty liver via activating AMPK and suppressing NF-kappaBp65 pathway. China J. Chin. Mater. Med. 2018, 43, 3176-3183.

49. Moraes-Vieira, P.M.; Saghatelian, A.; Kahn, B.B. GLUT4 Expression in Adipocytes Regulates De Novo Lipogenesis and Levels of a Novel Class of Lipids with Antidiabetic and Anti-inflammatory Effects. Diabetes 2016, 65, 1808-1815. [CrossRef] [PubMed]

50. Les, F.; Arbones-Mainar, J.M.; Valero, M.S.; Lopez, V. Pomegranate polypheno and urolithin A inhibit alpha-glucosidase, dipeptidyl peptidase-4, lipase, triglyceride accumulation and adipogenesis related genes in 3T3-L1 adipocyte-like cells. J. Ethnopharmacol. 2018, 220, 67-74. [CrossRef] [PubMed]

Sample Availability: Samples of the compounds are not available from the authors.

(C) 2019 by the authors. Licensee MDPI, Basel, Switzerland. This article is an open access article distributed under the terms and conditions of the Creative Commons Attribution (CC BY) license (http://creativecommons.org/licenses/by/4.0/). 